\title{
The Effect of the Projectile Shape on the Stress Biomechanical Behavior of Dental Implant: Three-dimensional Analysis
}

\author{
Noureddine Djebbar ${ }^{*}$, Boualem Serier², Smail Benbarek², Benali Boutabout ${ }^{2}$ \\ ${ }^{1}$ Laboratory Mechanical Physical of Materials (LMPM), Department of Mechanical Engineering, University of Hassiba Benbouali, \\ Essalem city, N 19 National Road, Chlef 02000, Algeria \\ ${ }^{2}$ Laboratory Mechanical Physical of Materials (LMPM), Department of Mechanical Engineering, University of Sidi Bel Abbes, \\ BP 89, Ben M'hidi city, Sidi Bel Abbes 22000, Algeria \\ * Corresponding author, e-mail: djebbarnour@yahoo.fr
}

Received: 25 May 2018, Accepted: 30 May 2019, Published online: 23 August 2019

\begin{abstract}
The finite element method is used to solve mechanical and physical problems in engineering analysis and design. Primary stability has been regarded as a prerequisite for osseointegration of dental implants. Biomechanical factors play a key role in the success of dental implants. The study of impact velocity is relevant to the biomechanics of dental implants. The purpose of this analysis was to determine the intensity and distribution of stresses in the dental prosthesis elements (crown, framework, implant, abutment, bone) and the sliding at the bone-implant interface under the effect of a mechanical impact of different geometric shape of projectile, this shock simulates a stone throw or other objects coming into contact with the dental prosthesis.
\end{abstract}

\section{Keywords}

finite element analysis, impact velocity, bone, biomechanics

\section{Introduction}

Nowadays, dental implants are the ideal solution for lack of dentition, being considered the best alternative after natural teeth. However, in spite of the latest advances in dentistry, implants are still likely to fail. Complications at the bone-implant interface, such as bone loss, occurrence of micromovements and stress concentration at the surface of the bone and the implant, are very common phenomena, which reveal the need of solution to keep the stability of the implant and the process of osseointegration. Dental implants have been highly successful in the rehabilitation of edentulous patients. However, they still suffer biological or mechanical failures $[1,2]$. The predictability of dental implants is affected by biologic, technical, and biomechanical factors [3]. The control of these factors is important to bone preservation $[4,5]$ and prosthetic complication reduction [6], which could extend the implant-supported rehabilitation success rate [7]. Recent development of digital imaging techniques made it possible to obtain subject-specific biological data of bone geometry and property for FEA modeling [8]. The finite element method (FEM) plays an important role today in solving engineering problems in many fields of science and industry and can be successfully applied in the simulations of biomechanical systems and dental implants [9]. Primary stability affects the strength, rigidity and resistance to movement of the implant before tissue healing and increases with increasing resistance to implant insertion [10]. The use of 3-D finite element methodology to analyze biomechanical clinical situations has been documented previously [11, 12] and [13]. Furthermore, the use of statistical analysis has been considered an effective tool in the finite element method [14]. The finite element analyses by Chang et al. [15] led to analyze the stress distribution in two popular commercial dental implant systems, containing different collar designs, with three-dimensional (3D) finite element models, which were performed using different bone qualities and different loading protocols. Hsu et al. [16] investigated the effects of three three-dimensional (3D) bone to implant contact (BIC) parameters potential BIC area (pBICA), BIC area (BICA), and 3D BIC percentage (3D BIC \%; defined as BICA divided by (pBICA) relation to the implant diameter on primary implant stability, as well as their correlations were also evaluated. 
Fellippo et al. [17] evaluated the stress distribution in single implant-supported prostheses placed over short implants and with different crown heights as the stress was transmitted to the bone tissue. In this study, improvements in simulation methods by integrating overload bone resorption have allowed for more accurate prediction of dental implants [18]. Predicted a non-homogeneous distribution of density/elastic modulus of the mandible around various dental implant systems [19]. Furthermore, by using a set of segmented algorithms, investigated bone remodeling around implant systems under different loading conditions, and recommended attaining proper occlusal adjustment to reduce the lateral force [20].

Therefore, the present study investigated the effect of the impact velocities by the different projectile shape on the stress distribution in the component of the dental structure using three-dimensional finite element models.

\section{Three-dimensional representation of bone-implant models}

\subsection{The mandibular bone}

The original 3D model of a mandibular bone section was constructed using computerized tomographic (CT) images (Fig. 1) [21, 22]. The stress analysis was performed using the ABAQUS 6.13 Software program. The bone was modeled as a cancellous core surrounded by a cortical layer. The width and height of cortical bone model were $15.8 \mathrm{~mm}$ and $23.5 \mathrm{~mm}$, respectively. The thickness of its upper part was $2 \mathrm{~mm}$ (Fig. 1).
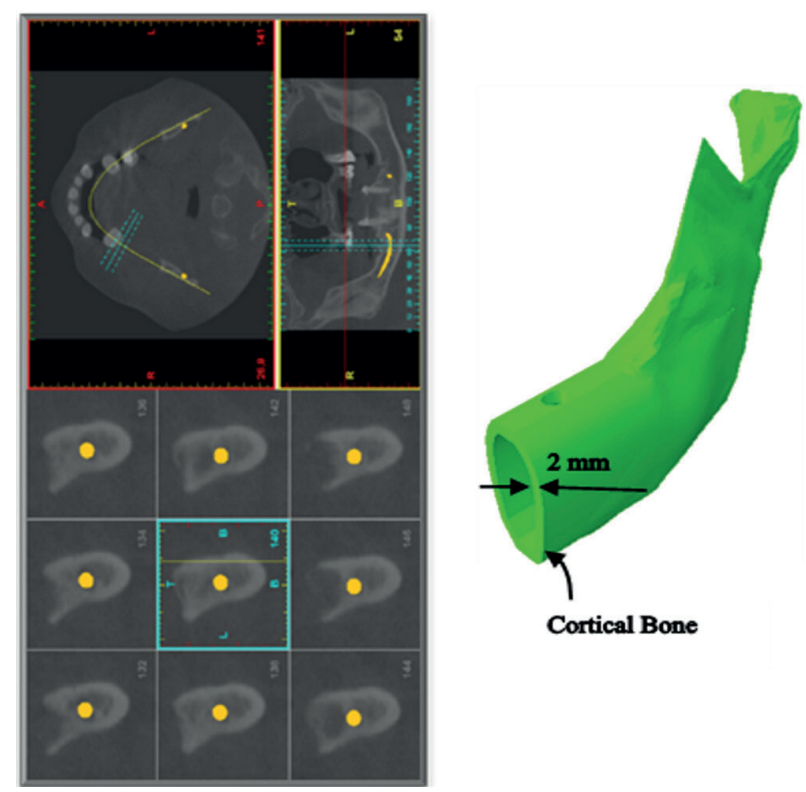

Fig. 1 CT scan mandibular bone.

\subsection{The implant system}

The geometry of the solid implant is presented in form of cylinder screw of length $14 \mathrm{~mm}$ and diameter $4.1 \mathrm{~mm}$. Abutment of conical form is adjusted to the implant. The sizes of the abutment are: length $1=7.2 \mathrm{~mm}$, lower diameter $d_{1}=2.6 \mathrm{~mm}$ and great diameter $d_{2}=3.6 \mathrm{~mm}$ [23-25]. The crown and framework model were designed in Rhinoceros 3D and SolidWorks 3D with $5^{\circ}$ inclination in bucco-lingual direction.

The complete model that consists of crown, framework, abutment, implant, cortical and cancellous bone (Fig. 2), were assembled using SolidWorks 2010 software, and then exported to Abaqus program (Fig. 3).

\subsection{Modeling contact}

Interaction between the bone and implant during simulation of the implantation process is complex and requires definition of contact conditions. In the present study,

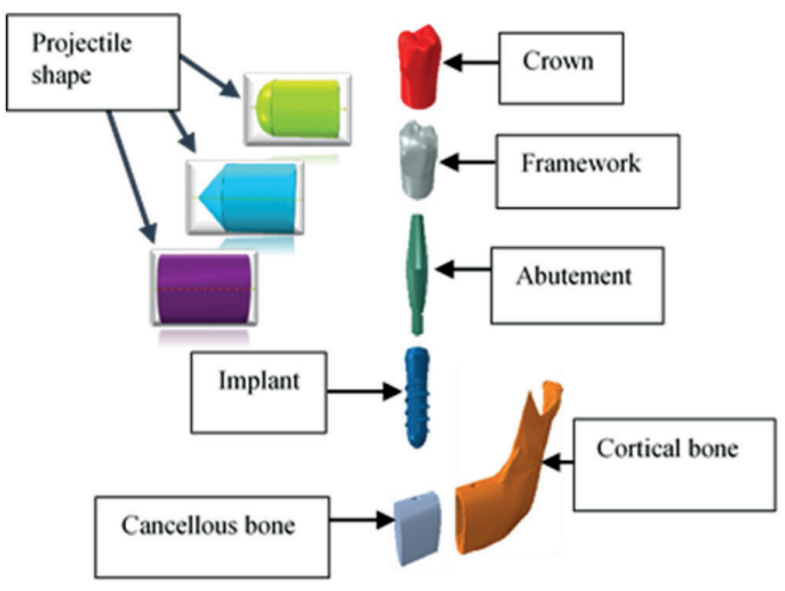

Fig. 2 Components of implants systems.

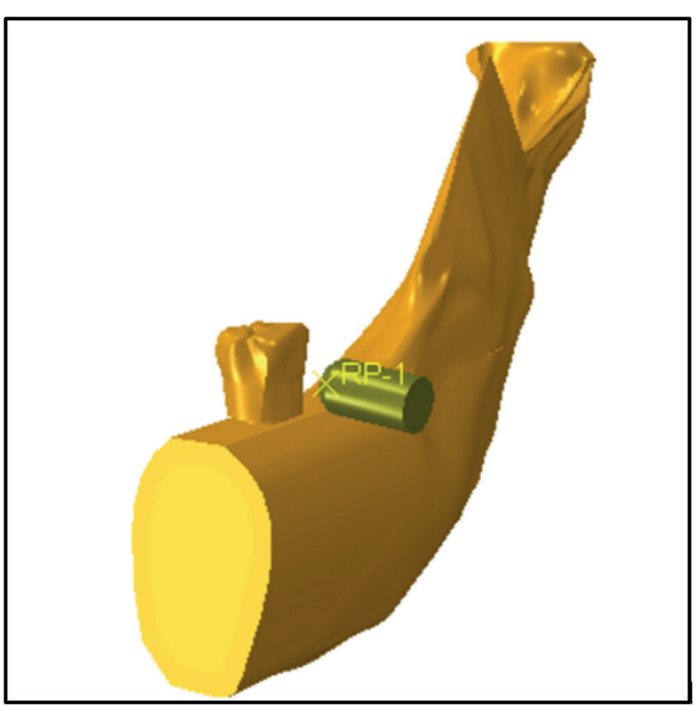

Fig. 3 Complete model of the structure. 
contact is defined in Abaqus software using surface-to-surface discretization because it provides stress that is more accurate and pressure results than node-to-surface discretization. Abaqus enforces conditional constraints on each surface to simulate contact conditions. In addition, the contact interaction properties are also required to be defined for the contact pair. The bone-implant interfaces were assumed to be 100\% osseointegrated (Fig. 3). Software (Abaqus 6.13; Dassault Systèmes Simulia Corp) was used for explicit dynamic simulation.

Table 1 gives the elastic properties of the components of the dental prosthesis $[24,25]$. The behavior of the cortical bone is supposed orthotropic. The projectile is taken as indeformed rigid body.

\subsection{Finite element model}

The tetrahedron elements with different sizes were used for the mesh in the implant, bone and projectile shape (Fig. 4 (a) and (b)).The crown of the dental prosthesis was meshed with 12435 tetrahedral elements and 23091 nodes. Framework also was meshed with 20118 tetrahedral elements besides 38466 nodes. A FE model of implant and abutement, in addition, were also meshed with 16269 and 7086 tetrahedral elements as well as 31874 and 14096 nodes, respectively. The cortical and cancellous bones, in addition, were meshed with 71769 and 46009 tetrahedral elements as well as 140544 and 91320 nodes, respectively. The total number of elements of three projectile shape was 47295 and the number of nodes was 95320. Since the interface of bone-implant experiences the largest deformations under load, it is necessary to mesh this boundary into small elements.

\subsection{Boundary condition and load application}

Following the creation of the 3D meshes, a boundary condition was applied to simulate the natural relationship of the implant complex supported by the bone structure.

Table 1 Mechanical properties of materials simulated.

\begin{tabular}{|c|c|c|c|}
\hline Parts & $\mathrm{E}(\mathrm{GPa})$ & $\begin{array}{l}\text { Poisson } \\
\text { ratio (v) }\end{array}$ & Reference \\
\hline Ti6A14V & 110 & 0.32 & [26-28] \\
\hline $\begin{array}{c}\text { Cobalt chrome } \\
\text { alloy }\end{array}$ & 220 & 0.30 & {$[29,30]$} \\
\hline $\begin{array}{c}\text { Feldsphatic } \\
\text { porcelain }\end{array}$ & 61.2 & 0.19 & {$[29,30]$} \\
\hline cortical & $\begin{array}{c}\mathrm{E}_{\mathrm{x}}=\mathrm{E}_{\mathrm{y}}=11.5 \mathrm{GPa}, \\
\mathrm{E}_{\mathrm{z}}=17 \mathrm{GPa}, \\
\mathrm{G}_{\mathrm{xy}}=3.6 \mathrm{GPa}, \\
\mathrm{G}_{\mathrm{xz}}=\mathrm{G}_{\mathrm{yz}}=3.3 \mathrm{GPa}\end{array}$ & $\begin{array}{c}v_{x y}=0.51 \\
v_{x z}=v_{y z}=0.3\end{array}$ & {$[27,31]$} \\
\hline cancellous & 2.13 & 0.3 & \\
\hline
\end{tabular}

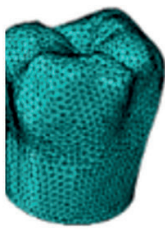

(a)
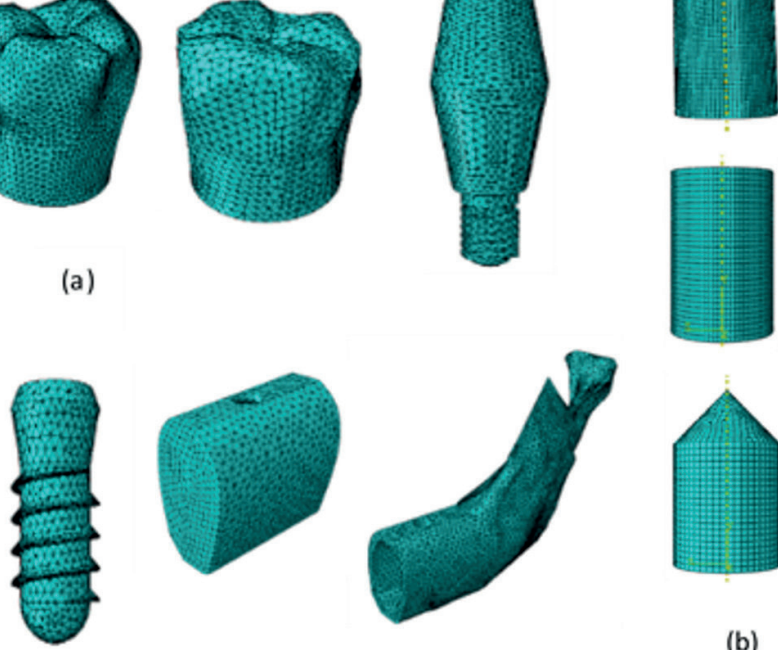

(b)
Fig. 4 The mesh of finite elements in the parts of: the implant structure (a), the projectile shape (b).

Thus a boundary condition (zero displacement) for the analysis purposes was defined at all nodes of the surfaces of the cortical bone that were constrained in all directions $(x, y$, and $z$ ) (Fig. 5). A tightening torque abutment-implant and implant-bone of 3500 N.mm and a friction coefficient of 0.28 were retained in the first step $[23,25]$. In the second step, Mass and Velocity are respectively considered as $50 \mathrm{~g}$ and $50 \mathrm{~m} / \mathrm{s}$, illustrated in Fig. 4 [32]. This impact velocities exerted on the crown after an accident of the patient.

\section{Results}

The response of the dental structure to the impact effect is analyzed here in terms of variation of the von Mises stress induced in all its components: Crown, Framework, Abutment, Implant, cortical and cancellous Bone. The results obtained are illustrated in the Figs. 6 to 10 .
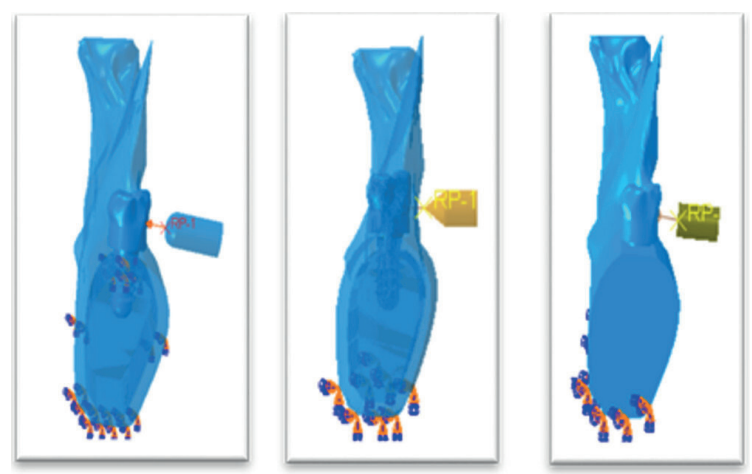

$$
\text { Boundary Conditions RP : Reference Point }
$$

Fig. 5 Applied impact and boundary conditions of the model. 


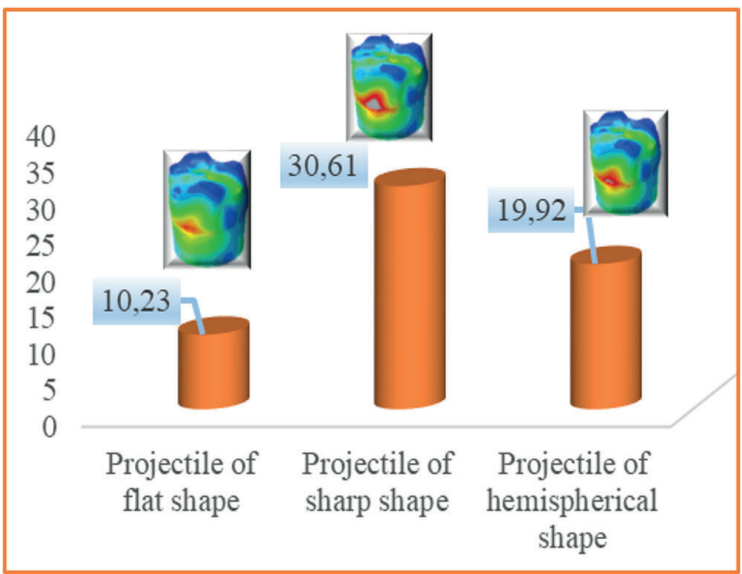

Fig. 6 Von Mises stress distribution in different projectile shape applied to the crown under impact velocity.

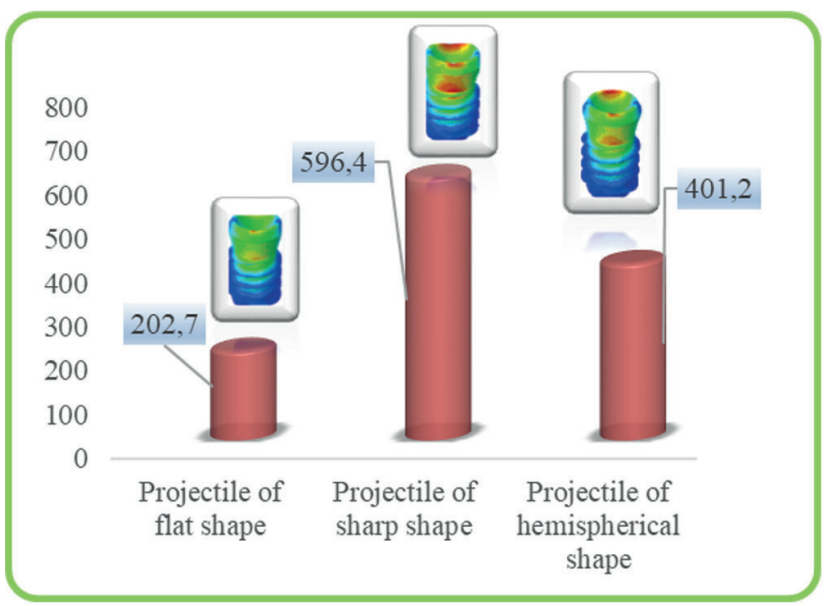

Fig. 7 Von Mises stress distribution in the implant in different projectile shape under impact velocity.

\subsection{FEA stress distribution in the crown, implant and abutement}

In the analysis, under impact velocity in different projectile shape, a specific analysis of the crowns showed a significant increase in the concentration of von Mises stresses in the projectile of flat shape to projectile of sharp shape. The highest stresses level were located mainly up to the face where the impact velocity are applied (Fig. 6). A projectile with pointed end (null radius of curvature), the stress intensity is very important. These stresses decrease in intensity when the radius of the projectile, in contact with the prosthesis, grows to tend towards infinite values (flat end).

The distribution of von Mises stress in the implant for different projectile shape under impact velocity is shown in Fig. 7. In the upper part of the implant, there is the region of strong stress concentration. The stresses are intensively

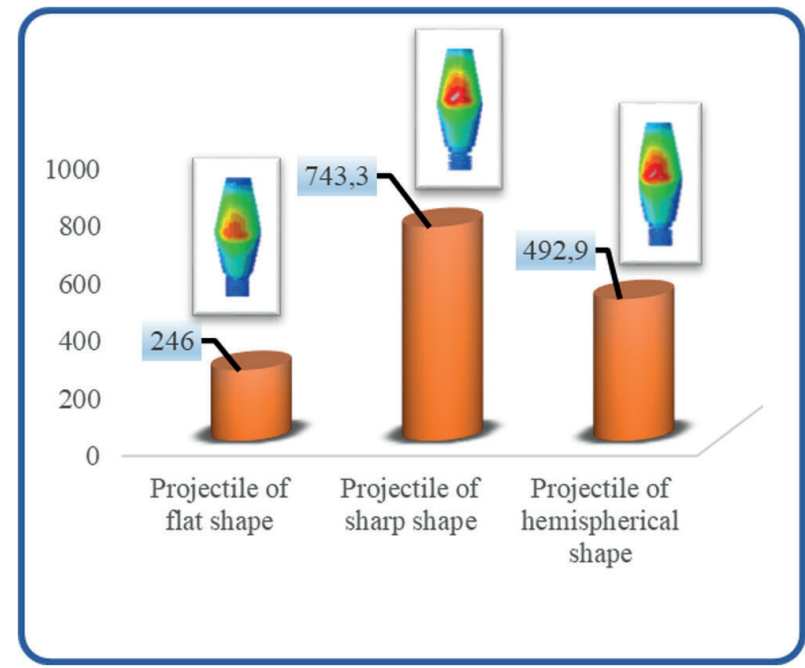

Fig. 8 Von Mises stress distribution in the abutement in different projectile shape under impact velocity.

distributed in the region of load application and in the opposed zone. The intensity of stresses is largely higher than that induced by the projectile of sharp shape. In the other zone of the implant, the stresses are almost uniformly distributed and their intensities remain low. The strongest stresses are located in the implant in the zone of strong interaction with the abutment under impact velocity in different projectile shape. We note, however, a similar behavior to the impact effect of the abutment (Fig. 8), the double and triple intensification factors were also observed.

\subsection{Bone tissue analysis}

FEA has become an important tool in the assessment of such biomechanical problems. The von Mises stresses in the bone are of importance as these are indicative of the problems that may arise with perfect sealing and early loosening of the implant. Fig. 9 and Fig. 10 shows the stress contours at the cancellous and cortical bone level for the three different shape of projectile under impact velocity.

The most fragile element in the dental structure is the bone (cancellous and cortical), its biomechanical behavior is strongly influenced by the effect of impact. Actually, a higher stress in cancellous and cortical bones were 30.61 and $166.3 \mathrm{MPa}$, which is high enough to invoke damage in these elements (Fig. 9 and Fig. 10). These figures show that during the projectile-crown collision, the most intense stresses are located on the upper part of the cortical bone (Fig. 10) and on its lower part (spongy bone), in the contact area with the implant (Fig. 9). This behavior is observed whatever the shape of the projectile end. The induced stress, under the effect of impact velocity, on the dental 


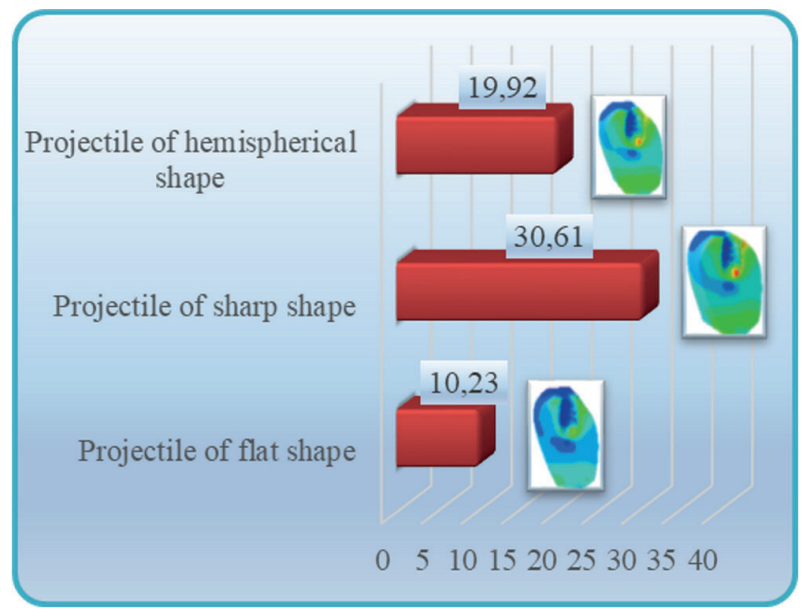

Fig. 9 Cross sectional view of von Mises stress distribution in the cancellous bone with different projectile shape under impact velocity.

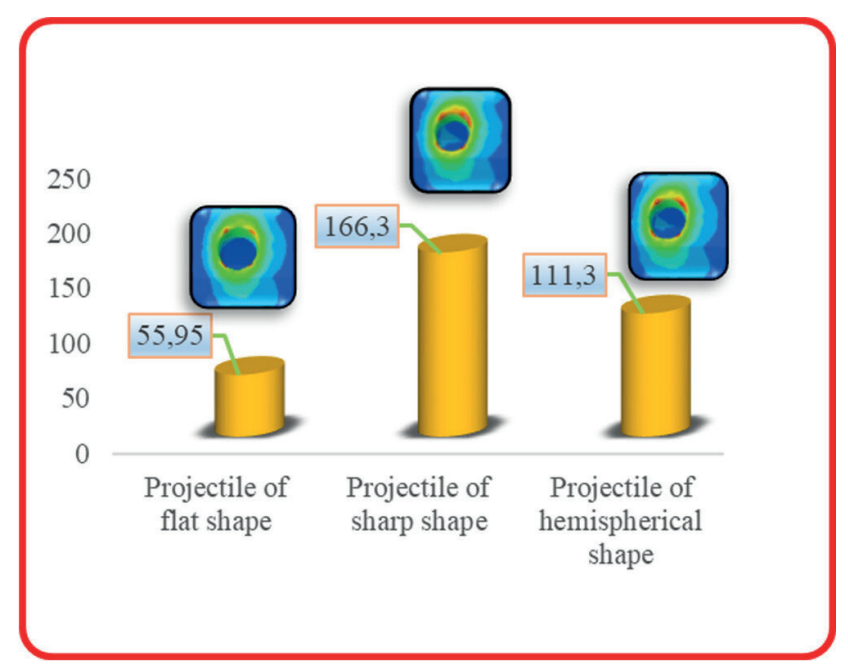

Fig. 10 Von Mises stress distribution in the cortical bone with different projectile shape under impact velocity.

prosthesis elements and particularly in the bone is high and can be fatal for the structure and the patient.

\subsection{Stress distribution along the interface bone-implant} In this part of work, we are interested only by the bone, because it represents the most fragile element in the dental structure analyzed. A key factor for the success or failure of a dental implant is the manner in which stresses are transferred to the surrounding bone.

Fig. 11 and Fig. 12 shows the variation of equivalent von Mises stress against true distance along the defined path in the cancellous bone for the different shape of projectile under impact velocity. The maximum values are observed at the distal zone in the cancellous bone and in upper part in the cortical bone, zones of intimate contact with the implant in the interface bone-implant. Our results clearly

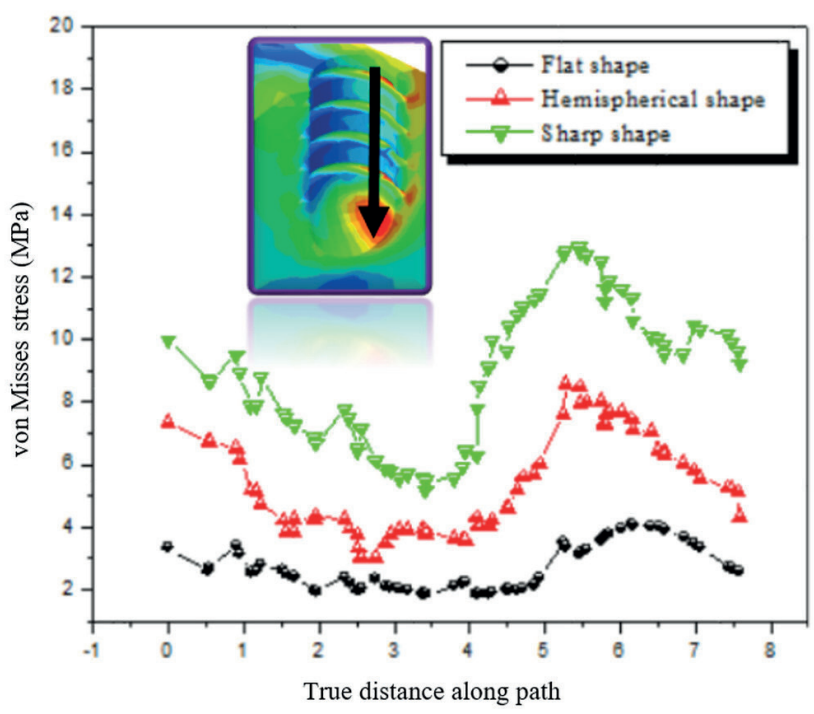

Fig. 11 Variations of von Mises stress against true distance along the defined path in the cancellous bone.

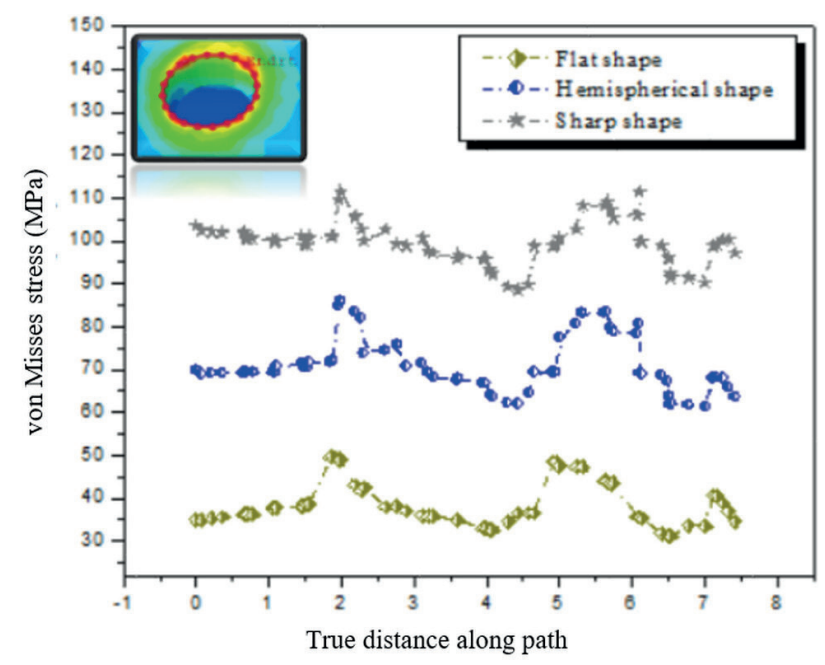

Fig. 12 Variations of von Mises stress against true distance along the cervical path in the cortical bone.

show, during the process of collision projectile-crown, the von Mises stress transmitted the bone by a sharp shape of projectile, largely exceeded the threshold of rupture of this living element. In such a case, the fracture of this bone is inevitable, leading to the ruin of the dental implantology, which would probably lead to a future interfacial rupture of the bone around the implant and therefore promotes damage to the dental prosthesis.

The maximum von Mises stresses of component dental prosthesis in the different projectile shape under impact velocity are illustrated in Fig. 13. The projectile of sharp shape generates in the structure dental the high level equivalent stress, its biomechanical behavior is strongly influenced by this form. These stresses decrease in intensity 
when the radius of the projectile, in contact with the prosthesis, grows to tend towards infinite values (flat end). A projectile with a sharp end (null radius of curvature) generates almost twice and three more intense and much more extensive stresses than those induced by hemispherical end projectiles (half-spherical radius of curvature) and flat end (infinite radius of curvature) respectively.

\section{Discussion}

The primary goal of the present study was to determine the level and distribution in the different dental structure component for different projectile shape under impact velocity. In the evaluation of the stresses on the dental implants, the highest stresses were observed on the parts of model in the zone of strong contact (strong interaction) [23-25, 33, 34]. Moreover, Chang et al. [35] reviewed the available evidence on the response of the peri-implant bone when subjected to excessive occlusal forces.

As seen in Fig. 13, the evaluation of the maximum von Mises stresses on the elements of dental prosthesis, the impactor with acute end generate stress that are too high level in the bone. Because of the contact of close friend to the bone interface and implant, the impact loading applied to the crown is directly transmitted to the cancellous bone (the least resistant element), which can lead to the ruin and thus to the interfacial rupture of the bone around the implant.

\section{Conclusion}

The finite element analysis (FEA) of the stress distribution in the implant, abutment, cortical and trabecular bone of the atrophied mandible for the impact loading in three different projectile shape revealed:

- The most significant Von Mises stress is located on the impacted zone. Far from this zone the stress

\section{References}

[1] Abu-Hammad, O., Khraisat, A., Dar-Odeh, N., Jagger, D. C., Hammerle, C. H. "The staggered installation of dental implants and its effect on bone stresses", Clinical Implant Dentistry and Related Research, 9(3), pp. 121-127, 2007. https://doi.org/10.1111/j.1708-8208.2007.00055.x

[2] Faegh, S., Müftü, S. "Load transfer along the bone-dental implant interface", Journal of Biomechanics, 43(9), pp. 1761-1770, 2010. https://doi.org/10.1016/j.jbiomech.2010.02.017

[3] Wennerberg, A., Albrektsson, T. "Current challenges in successful rehabilitation with oral implants", Journal of Oral Rehabilitation, 38(4), pp. 286-294, 2011.

https://doi.org/10.1111/j.1365-2842.2010.02170.x

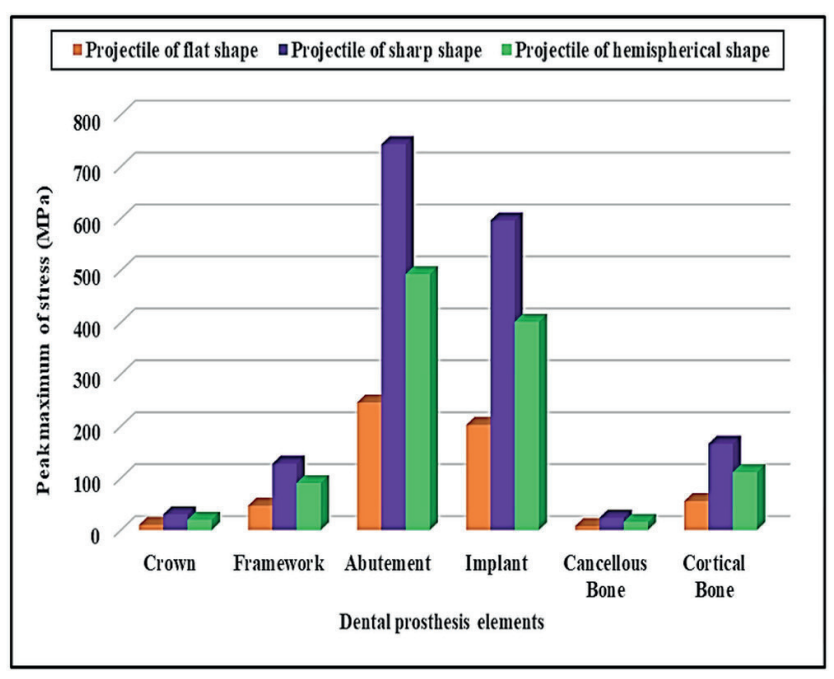

Fig. 13 Diagrams illustrating the comparison of maximum von Mises stress $(\mathrm{MPa})$ of components implant systems in different projectile shape applied to crown under impact velocity.

tends to totally relax. Whatever the shape of the projectile, the impacted zone is the seat of stress concentration;

- The Von Mises stress in the impacted part is higher the smaller the radius of curvature. This form results from the stresses in all the components of the dental structure, three times more intense than those produced by a flat-ended projectile and twice as great as that resulting from an impactor with a hemispherical end;

- The projectile-crown collision process results in a transfer of charge from the crown to the bone, this transfer is all the more intense as the radius of curvature of the end of the projectile tends to be zero. This transfer leads to damage to the dental prosthesis by fracture of the cortical bone. The stresses observed in this component are much greater than its breaking point.

[4] Lin, C.-L., Lin, Y.-H., Chang, S.-H. "Multi-factorial analysis of variables influencing the bone loss of an implant placed in the maxilla: prediction using FEA and SED bone remodeling algorithm", Journal of Biomechanics, 43(4), pp. 644-651, 2010. https://doi.org/10.1016/j.jbiomech.2009.10.030

[5] Lin, D., Li, Q., Li, W., Duckmanton, N., Swain, M. "Mandibular bone remodeling induced by dental implant", Journal of Biomechanics, 43(2), pp. 287-293, 2010. https://doi.org/10.1016/j.jbiomech.2009.08.024

[6] Goodacre, C. J., Bernal, G., Rungcharassaeng, K., Kan, J. Y. K. "Clinical complications with implants and implant prostheses", The Journal of Prosthetic Dentistry, 90(2), pp. 121-132, 2003. https://doi.org/10.1016/S0022-3913(03)00212-9 
[7] Manfredini, D., Poggio, C. E., Lobbezoo, F. "Is bruxism a risk factor for dental implants? A systematic review of the literature", Clinical Implant Dentistry and Related Research, 16(3), pp. 460-469, 2012. https://doi.org/10.1111/cid.12015

[8] Shigemitsu, R., Yoda, N., Ogava, T., Kawata, T., Gunji, Y., Yamakawa, Y., Ikeda, K., Sasaki, K. "Biological-data-based finite-element stress analysis of mandibular bone with implant-supported overdenture", Computers in Biology and Medicine, 54, pp. 44-52, 2014.

https://doi.org/10.1016/j.compbiomed.2014.08.018

[9] Będzinski, R. "Biomechanical Engineering", Publishing House Technical University of Wroclaw (Oficyna Wydawnicza Politechniki Wroclawskiej), Wroclaw, Poland, 1997.

[10] Elias, C. N., Rocha, F. A., Nascimento, A. L., Coelho, P. G. "Influence of implant shape, surface morphology, surgical technique and bone quality on the primary stability of dental implants", Journal of the Mechanical Behavior of Biomedical Materials, 16, pp. 169-180, 2012.

https://doi.org/10.1016/j.jmbbm.2012.10.010

[11] de Faria Almeida, D. A., Pellizzer, E. P., Verri, F. R., Santiago Jr., J. F., de Carvalho, P. S. P. "Influence of tapered and external hexagon connections on bone stresses around tilted dental implants: three-dimensional finite element method with statistical analysis", Journal of Periodontology, 85(2), pp. 261-269, 2014. https://doi.org/10.1902/jop.2013.120713

[12] Faegh, S., Müftü, S. "Load transfer along the bone-dental implant interface", Journal of Biomechanics, 43(9), pp. 1761-1770, 2010. https://doi.org/10.1016/j.jbiomech.2010.02.017

[13] Chou, H.-Y., Müftü, S. "Simulation of peri-implant bone healing due to immediate loading in dental implant treatments", Journal of Biomechanics, 46(5), pp. 871-878, 2013.

https://doi.org/10.1016/j.jbiomech.2012.12.023

[14] Pellizzer, E. P., Verri, F. R., Falcón-Antenucci, R. M., Santiago Júnior, J. F., de Carvalho, P. S. P., de Moraes, S. L. D., Noritomi, P. Y. "Stress analysis in platform-switching implants: a 3-dimensional finite element study", Journal of Oral Implantology, 38(5), pp. 587-594, 2012.

https://doi.org/10.1563/AAID-JOI-D-10-00041

[15] Chang, H.-S., Chen, Y.-C., Hsieh, Y.-D., Hsu, M.-L. "Stress distribution of two commercial dental implant systems: A three-dimensional finite element analysis", Journal of Dental Sciences, 8(3), pp. 261-271, 2013. https://doi.org/10.1016/j.jds.2012.04.006

[16] Hsu, J.-T., Shen, Y.-W., Kuo, C.-W., Wang, R.-T., Fuh, L.-J., Huang, H.-L. "Impacts of 3D bone to implant contact and implant diameter on primary stability of dental implant", Journal of the Formosan Medical Association, 12(8), pp. 1-9, 2017. https://doi.org/10.1016/j.jfma.2017.05.005

[17] Verri, F. R., Santiago Junior, J. F., de Faria Almeida, D. A., de Oliveira, G. B. B., de Souza Batista, V. E., Honório, H. M., Noritomi, P. Y., Pellizzer, E. P. "Biomechanical influence of crown-to-implant ratio on stress distribution over internal hexagon short implant: 3-D finite element analysis with statistical test", Journal of Biomechanics, 48(1), pp. 138-145, 2015.

https://doi.org/10.1016/j.jbiomech.2014.10.021
[18] Li, J., Li, H., Shi, L., Fok, A. S. L., Ucer, C., Devlin, H., Horner, K., Silicas, N. "A mathematical model for simulating the bone remodeling process under mechanical stimulus", Dental Materials, 23(9), pp. 1073-1078, 2007. https://doi.org/10.1016/j.dental.2006.10.004

[19] Chou, H.-Y., Jagodnik, J. J., Müftü, S. "Predictions of bone remodeling around dental implant systems", Journal of Biomechanics, 41(6), pp. 1365-1373, 2008.

https://doi.org/10.1016/j.jbiomech.2008.01.032

[20] Ammar, H. H., Ngan, P., Crout, R. J., Mucino, V. H., Mukdadi, O. M. "Three dimensional modeling and finite element analysis in treatment planning for orthodontic tooth movement", American Journal of Orthodontics and Dentofacial Orthopedics, 139(1), pp. 59-71, 2011. https://doi.org/10.1016/j.ajodo.2010.09.020

[21] Wang, Z., Zhao, Z., Xue, J., Song, J., Deng, F., Yang, P. "Pullout strength of mini screws placed in anterior mandibles of adult and adolescent dogs: a microcomputed tomographic analysis", American Journal of Orthodontics and Dentofacial Orthopedics, 137(1), pp. 100-107, 2010. https://doi.org/10.1016/j.ajodo.2008.01.025

[22] Zhao, L., Xu, Z., Yang, Z., Wei, X., Tang, T., Zhao, Z. "Orthodontic mini-implant stability in different healing times before loading: a microscopic computerized tomographic and biomechanical analysis", Oral Surgery, Oral Medicine, Oral Pathology, Oral Radiology, and Endodontology, 108(2), pp. 196-202, 2009. https://doi.org/10.1016/j.tripleo.2009.03.023

[23] Djebbar, N., Serier, B., Bouiadjra, B. B., Benbarek, S., Drai, A. "Analysis of the effect of load direction on the stress distribution in dental implant", Materials and Design, 31(4), pp. 2097-2101, 2010. https://doi.org/10.1016/j.matdes.2009.10.042

[24] Achour, T., Merdji, A., Bouiadjra, B. B., Serier, B., Djebbar, N. "Stress distribution in dental implant with elastomeric stress barrier", Materials and Design, 32(1), pp. 282-290, 2011. https://doi.org/10.1016/j.matdes.2010.05.053

[25] Djebbar, N., Serier, B., Bouiadjra, B. B. "Finite element analysis in static and dynamic behaviors of dental prosthesis", Structural Engineering and Mechanics, 55(1), pp. 65-78, 2015. https://doi.org/10.12989/sem.2015.55.1.065

[26] Bonnet, A. S., Postaire, M., Lipinski, P. "Biomechanical study of mandible bone supporting a four implant retained bridge finite element analysis of the influence of bone anisotropy and foodstuff position", Medical Engineering and Physics, 31(7), pp. 806-815, 2009. https://doi.org/10.1016/j.medengphy.2009.03.004

[27] Sevimay, M., Usumez, A., Eskitascioglu, G. "The influence of various occlusal materials on stresses transferred to implant-supported prostheses and supporting bone: a three-dimensional finite element study", Journal of Biomedical Materials Research Part B Applied Biomaterials, 73B(1), pp. 140-147, 2005. https://doi.org/10.1002/jbm.b.30191

[28] Zhu, J.-W., Yang, D.-W., Fai, M. "Investigation of a new design for zirconia dental implants", Journal of Medical Colleges of PLA, 22(5), pp. 303-311, 2007. https://doi.org/10.1016/S1000-1948(07)60062-8 
[29] Kayabasi, O., Yuzbasioglu, E., Erzincanli, F. "Static, dynamic and fatigue behaviours of dental implant using finite element method", Advances in Engineering Software, 37(10), pp. 649-658, 2006. https://doi.org/10.1016/j.advengsoft.2006.02.004

[30] Merdji, A., Bouiadjra, B. B., Achour, T., Serier, B., Chikh, B. O., Feng, Z. O. "Stress analysis in dental prosthesis", Computational Materials Science, 49(1), pp. 126-133, 2010. https://doi.org/10.1016/j.commatsci.2010.04.035

[31] Kitagawa, T., Tanimoto, Y., Odaki, M., Nemoto, K., Aida, M. "Influence of implant/abutment joint designs on abutment screw loosening in a dental implant system", Journal of Biomedical Materials Research Part B Applied Biomaterials, 75B(2), pp. 457-463, 2005. https://doi.org/10.1002/jbm.b.30328

[32] Shemtov-Yona, K., Rittel, D., Dorogoy, A. "Mechanical assessment of grit blasting surface treatments of dental implants", Journal of the Mechanical Behavior of Biomedical Materials, 39, pp. 375-390, 2014.

https://doi.org/10.1016/j.jmbbm.2014.07.027
[33] Verri, F. R., Santiago Junior, J. F., de Faria Almeida, D. A., de Oliveira, G. B. B., de Souza Batista, V. E., Honorio, H. M., Noritomi, P. Y., Pellizzer, E. P. "Biomechanical influence of crown-to-implant ratio on stress distribution over internal hexagon short implant: 3-D finite element analysis with statistical test", Journal of Biomechanics, 48(1), pp. 138-145, 2015. https://doi.org/10.1016/j.jbiomech.2014.10.021

[34] Minatel, L., Verri, F. R., Kudo, G. A. H. de Faria Almeida, D. A., de Souza Batista, V. E., Lemos, C. A. A., Pellizzer, E. P., Santiago Junior, J. F. "Effect of different types of prosthetic platforms on stress-distribution in dental implant-supported prostheses", Materials Science and Engineering: C, 71, pp. 35-42, 2017. https://doi.org/10.1016/j.msec.2016.09.062

[35] Chang, M., Chronopoulos, V., Mattheos, N. "Impact of excessive occlusal load on successfully osseointegrated dental implants: a literature review", Journal of Investigative and Clinical Dentistry, 4(3), pp. 142-150, 2013.

https://doi.org/10.1111/jicd.12036 